\title{
RFID-Based Logistics Technology of Laboratory Equipments in University
}

\author{
Renshang Zhang ${ }^{1 *}$ and Ahmed Oulad Reha ${ }^{2}$ \\ ${ }^{1}$ Faculty of Information Management, Shanxi University of Finance and Economics, Taiyuan 030006, China \\ ${ }^{2}$ Department of Telecommunications Engineering, Higher Institute of Applied Engineering (IGA), Marrakesh, Morocco
}

\begin{abstract}
With the popularity of Chinese education and the progress and development of higher education, in order to further enhance their own school-running level and teaching quality as well as improve the level of the teachers, universities has been constantly introducing advanced teaching laboratory equipments. On the one hand, it not only can help the teachers with their teaching, but also can well improve the students' learning efficiency. However, there are also many problems existed in management of the large number of laboratory equipments, for the traditional artificial unintelligent managing way of using pen and paper in daily record already cannot meet the needs of the presented situation. Collecting data by manhood will cause such problems as collecting not in time or collecting incorrectly. And collecting data by manhood puts forward higher request for laboratory managers in equipment management. But if increase the laboratory management personnel, it also causes problems such as the waste of human resources and the increased cost of school management, etc. The presented research, mainly by using the experience and thought in management of logistics field for reference, makes a research on the application of laboratory equipment management in colleges and universities based on RFID logistics technology to solve the problems exited in the management of laboratory equipments. Using real-time monitoring laboratory equipment and intelligent tracking laboratory equipments to record and verify information can reduce the workload of lab manager and strengthen the way and the level of the laboratory management. At the same time, it also can enables the superior managers to timely master the status of school laboratory equipment, accelerating the informational construction of universities and colleges, further optimizing the configuration of teaching laboratory equipment, and fully improving usage rate of the school laboratory equipment.
\end{abstract}

Keywords: RFID, logistics management, laboratory equipment, informational management.

\section{INTRODUCTION}

With the development of science and technology, electronic commerce also develops in a rapid speed. The expansion of the application field, directly leads to the development and changes in logistics field. In traditional logistics, the company will send staff to make the delivery one by one according the customers' address or determine a fixed position to let customers to pick up the package by themselves. However, with the rapid development of the logistics industry, not only the quantity shows rapid growth trend, but also the volume of the package becomes larger. Still adopting the traditional method to send or collect the packages will lead to great problems such as relatively low work efficiency, the heavy workload of the staff, and difficulty in reading the data information of the objects. RFID technology is introduced based on this issue, fully reducing the cost in human resources, time and other aspects of each enterprise as well as improving the timeliness and correctness of collecting the product information in the process of circulation, so that enterprises can manage logistics goods better.

With the continuous development and progress of China's education business, universities and colleges in China have introduced advanced equipment to be used in teaching activities. The increase input to higher institutions by the country increases the number of laboratory equipments of colleges and universities. However, all colleges and universities are also facing with a serious problem that how to effectively manage the increasing number of equipment. The traditional management mode has been unable to meet the requirements of development of the school. Therefore, based on the perfect experience of the RFID logistics technology using in logistics management, apply the RFID logistics technology into management system of college laboratory equipments to improve the managing efficiency of school equipments. It can provide laboratory equipment information better, and statistically analyze the data to provide data support for the post maintenance management. The managing personnel of the laboratory equipment can timely, accurately grasp the situation of the testing usage of the laboratory equipments, and arrange the usage of equipment reasonably so to improve the work efficiency.

\section{THE WORKING PRINCIPLES AND CHARACTER- ISTICS OF RFID}

\subsection{The Composition of the RFID System}

RFID (Radio Frequency Identification [1]) technology is a non-contact automatic identification technology, which can automatically identify and collect data through the radio fre- 


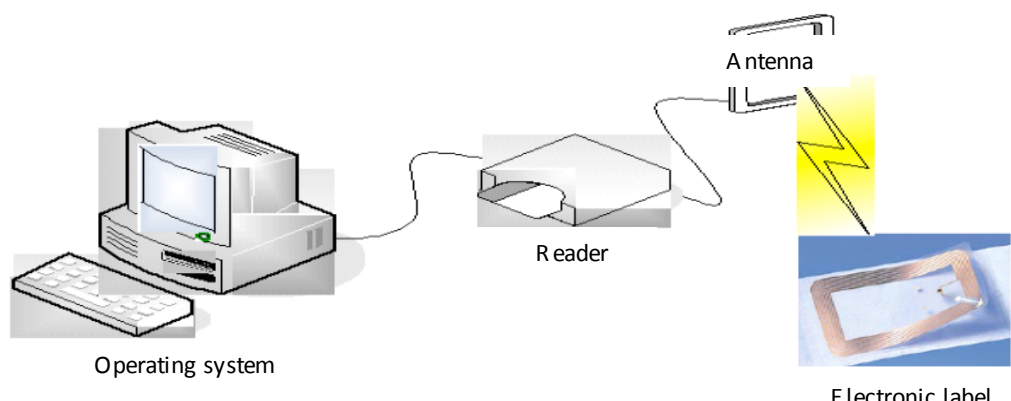

The whole RFID system

Fig. (1). Sketch of the working principle of RFID system.

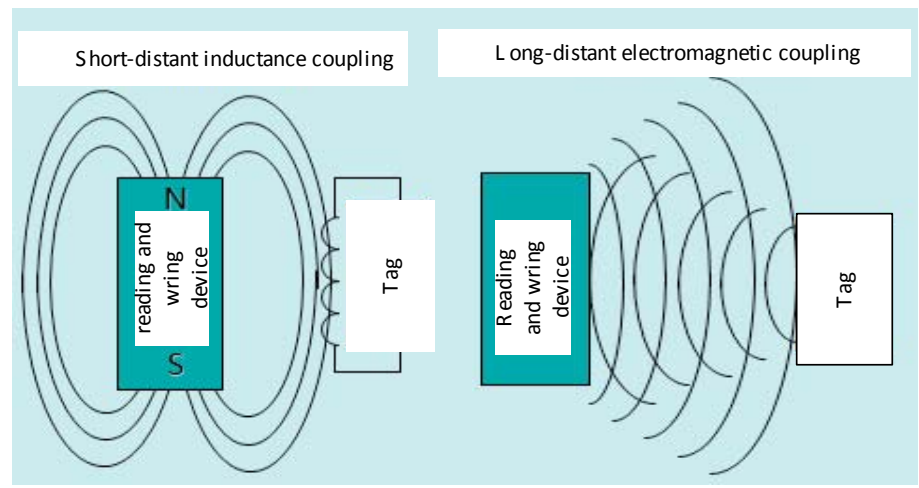

Fig. (2). Two working mechanisms of RFID.

quency signals, and needs no artificial participation when at work. It also can work well under the condition of severe environment, and has strong ability of adaptation. In addition, RFID radio frequency identification device also can be used in high speed moving objects and to identify multiple tags, which means it has wide range of application and the operation is relatively simple. At present, the field which the RFID technology applies into is very broad, and it is now a very important technique in the research of application field.

RFID is quite similar with barcode scanning and it works mainly by using special reading and writing device and the tag unit. By the electromagnetic frequency, communication between the writing and reading device and the tag can be achieved so as to realize the data reading, rewriting and storage etc. The RFID system is mainly composed of tags, readers, the antenna and a computer system [2]. The tag is mainly composed of a chip, which is carried the fixed information such as ID inside, antenna and carrier, and electronic coding of each tag is unique that is posted on the target object [3]. The reader mainly carries the operations of reading and wrings the tag and is usually designed in handheld version. Antenna is the way of communication, realizing information transmission between the reader and tag. First of all, through the antenna, the reader sends a radio frequency identification signal with fixed frequency. When the tag goes into the magnetic field, it can generate an induction current and gains. Then the tag sends to the reader their own code and other related information, while the latter receives these data and begin the decoding work. Finally the reader will send collected data to the mainframe in the background for operating treatment shown as Fig. (1) According to the differences of the working mechanisms, RFID system can be divided into the electromagnetic coupling and inductance coupling, shown as Fig. (2).

\subsection{The Advantages of the RFID Technology}

At present, there are many widely used identification technologies, each of which have their own characteristic and can respectively be used in different occasions. The differences between RFID and other identification technologies are shown in Table 3 .

The advantages of RFID technology mainly are presented in the following five aspects:

\section{(1) Great ability of reading and wring data}

Data reading and writing operation only needs to be within the reader's reading scope, with no requirements for close contact, to read the information in the tag and store it in the database. The reader can read and write multiple tags at one time, and has high working efficiency. And the state in logistics department can be written into the tag, providing data for retainer system in next work point of logistics department.

\section{(2) Diversification and miniaturization of the shape}

RFID is not limited by the size and shape in the read operation, and does not need to deliberately use the corresponding size of the paper to read the high accuracy data information which will define the size and printing quality of the product [4]. RFID tag is capable of miniaturizing production and application in various products, making it more convenient to control the batch production of product. 
Table 3. The difference between RFID and other identification technology.

\begin{tabular}{|c|c|c|c|c|c|}
\hline & Information Carrier & $\begin{array}{c}\text { Amount of } \\
\text { Information }\end{array}$ & Read / Write & Read Mode & Confidentiality \\
\hline \hline Bar code & $\begin{array}{c}\text { Paper, plastic, metal } \\
\text { surface }\end{array}$ & Small & Read / write & $\begin{array}{c}\text { Electromagnetic con- } \\
\text { version }\end{array}$ & Pcanning \\
\hline Magnetic card & Magnetic material & Middle & Read / write & $\begin{array}{c}\text { Electrically erase, write } \\
\text { in }\end{array}$ & General \\
\hline IC card & Eeprom & Large & Read / write & Wireless communica- \\
tion
\end{tabular}

(3) Strong ability to adapt to the environment

The usual paper tags are easy to get dirty or damaged, and once suffered from being damaged or polluted, the information on the paper will be unable to be read. But RFID has strong ability to resist the pollution such as water, oil, drugs and other substances. In addition, RFID is able to properly read data in poor light or harsh circumstances.

(4) Ability of being used repeatedly

Being as an electric tag, RFID can be used repeatedly. Electronic tags can be repeatedly modified and recycled. For example, the passive RFID needs no batteries to provide power to work, and no maintenance or warranty requirements.

(5) A large amount of data memory

With the development of memory specifications, data capacity can be constantly expanding and contained information of the future item will be larger and larger, which will demand a relatively large expanding capacity of the tag [5], But RFID will not be limited by this situation.

\section{RESEARCH ON THE APPLICATION OF RFID LOGISTICS TECHNOLOGY IN THE SYSTEM OF LABORATORY EQUIPMENT MANAGE- MENT}

Because the present universities are using traditional sticking card of production equipment or other paper labels to make marks, and inputting data by the managing personnel of the equipments. There will be problems such as a heavy work of staff and being prone to errors for requiring registration of each product. In order to change the backward laboratory equipment management method and realize the information of laboratory management system, a novel management way, which draws on experience of applying RFID in logistics to put tag to each experimental device and then collect data through the handheld reader, is used.3.1. Analysis on application of RFID technology in the field of logistics RFID technology is mainly applied into the links of production, warehouse storage, transportation and distribution of the logistics.

(1) Production. Once a product reaches the fixed position on the assembly line, its parts will be the assembled by the operating personnel, and it will be labeled the RFID tag and then put back on the assembly line. The product with electronic tag will go through the reader which will read the information of each product and transmit them to the computer of in back.

(2) Warehouse storage: Because there are many goods stored in the warehouse, in order to locate each product quickly, the RFID tag could be labeled on the warehouse goods location, container, pallet and etc. The label contains the specification of the components, serial number and other relevant information. Through the usage of electronic tags to represent the goods, trays, containers and so on, every movements of each item will be recorded by the electronic tag and reader, which will enable the warehouse management personnel to grasp the information quickly and accurately. Fig. (3) shows the management system of RFID intelligent warehouse.

(3) Product transportation: The information of products could be obtained in the process of transportation through reading the tag by the reader if the product is labeled by the tag. The position information is transmitted to the dispatching center of goods, so that logistics distribution information could be updated timely and accurately [6]. So once there comes any problems about goods delivery, it can be quickly grasped and timely resolved, preventing the occurrence of the goods lost or being stolen.

(4) Product delivery: When products affixed with electronic tag item is delivered to the destination, all the infor- 


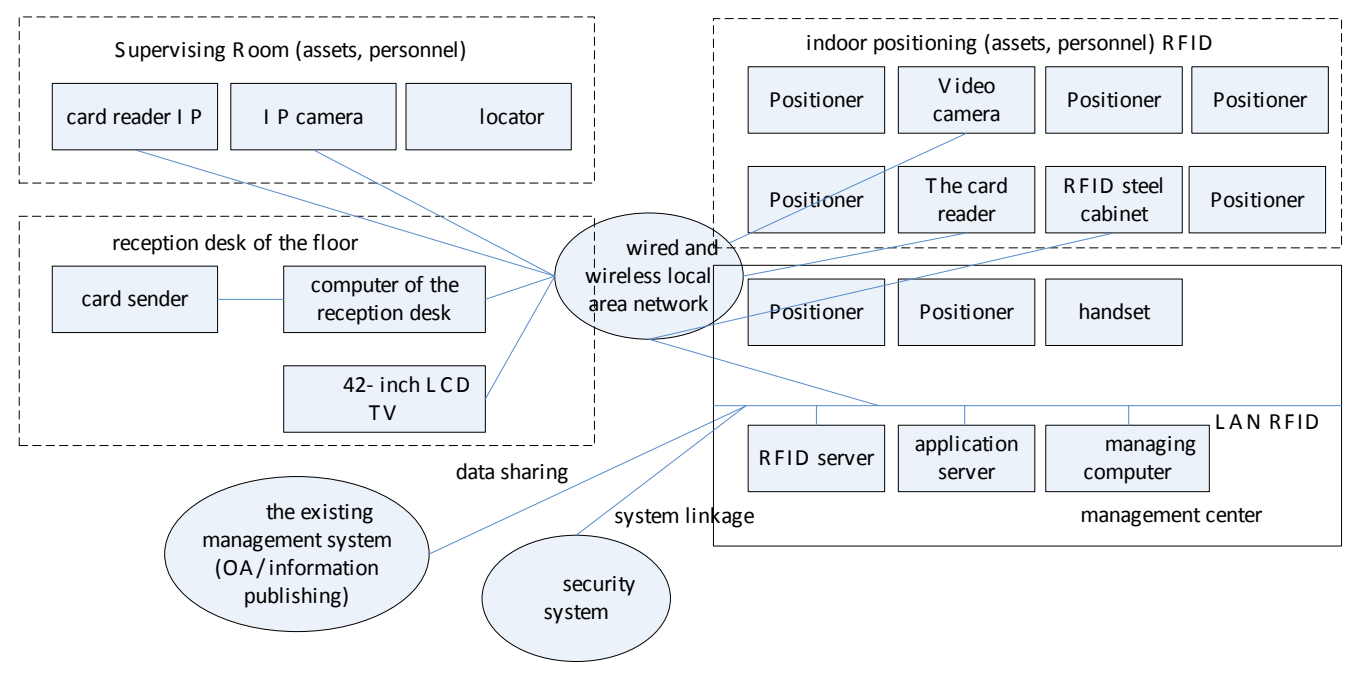

Fig. (3). Management system of RFID intelligent warehouse.

mation of the products on the tray can be read by reader at the entrance and the data will be sent to the computer system of the background to check. The condition and storage location of the product will be updated immediately after the goods being checked, so that all the information of the products could be under control from sending palace to destination.3.2. Features of the information management and structure design of management system.

The new laboratory equipment management system has many advantages, and now all the information of the laboratory equipment can be stored directly to the electronic tag. Electronic tag could work for a long time, and is not easy to be damaged. Even under harsh environmental condition, it can work well, so that it is possible to inquiry the original information at anytime and everywhere. The handheld terminal reader makes it convenient for the managers to make the statistics of the laboratory equipment information which largely reduces the workload of the managers. The data collected into the laboratory equipment is very accurate, and the speed of the collection is more rapid and convenient. Even when laboratory equipment is broken and needs to be replaced with the new equipment, as the electronic tag is reusable, the tag can be used continually only by rewriting which will save a part of the funds of replacement.

The information management system based on RFID technology of university laboratory equipment mainly includes the following functional modules: controlling module of laboratory equipment in to and out of the lab, statistical module of laboratory equipment stored position and quantity information, query module of automatic information. Laboratory management personnel can make the statistics conveniently, and real-timely control the operation status of the laboratory equipment. And if the system is connecting to the LAN, related superior leadership can do the supervision at any time.

The whole laboratory equipment management system mainly includes the location reading and writing device, monitoring system, and hand-held reader, and the system structure of informational laboratory is shown in Fig. (4). The PC machine needs to install some prerequisite software, and to be able to connect with all the reading and writing devices, reading and recording the information of laboratory equipment which Includes detailed information as product name, manufacturer, production time, product type, using time. The reader can be placed in front of the lab's door, so that whenever there is a device affixed with the electronic tag goes through, the reader can read the related information of the device timely and send the data back to the PC, updating the data in the database is [7].

In addition, installing monitoring equipment out of the laboratory's door could monitor all the incoming and outgoing equipments, as well as the personnel information, preventing the device from being stolen. In the monitoring area of the video monitor, the identifier can transmit a fixed frequency. When there is radio-frequency signal enters the monitoring area, the monitoring device will automatically trigger the alarm device. The portable handheld reader can readily collect information of the tags on various laboratory devices, having a strong flexibility. The read information can either promptly uploaded to the host PC in the background or be temporarily stored in the reader, making it easy to find relevant laboratory equipment [8]. Thus, as long as the device goes out of the laboratory's door, the registration will be made timely, achieving real-time updates of data, and greatly reducing the workload of staff. In the regular inventory of laboratory equipment by the managers, managers can simply use the handheld devices to scan the electronic tag to make the statistics of the quantitative information of the laboratory equipments, which fully saves the time for the staff.

\section{CONCLUSIONS}

The application of information management system in university laboratory equipment based on the RFID logistics technology not only solves the traditional problems of laboratory equipment management, but also achieves automation and information of management for the university laboratory equipments. The level of higher education will be improved, and at the same time laboratory equipments can be managed and controlled reasonably, giving full play to the role of laboratory equipments, and forming the intelligent manage- 


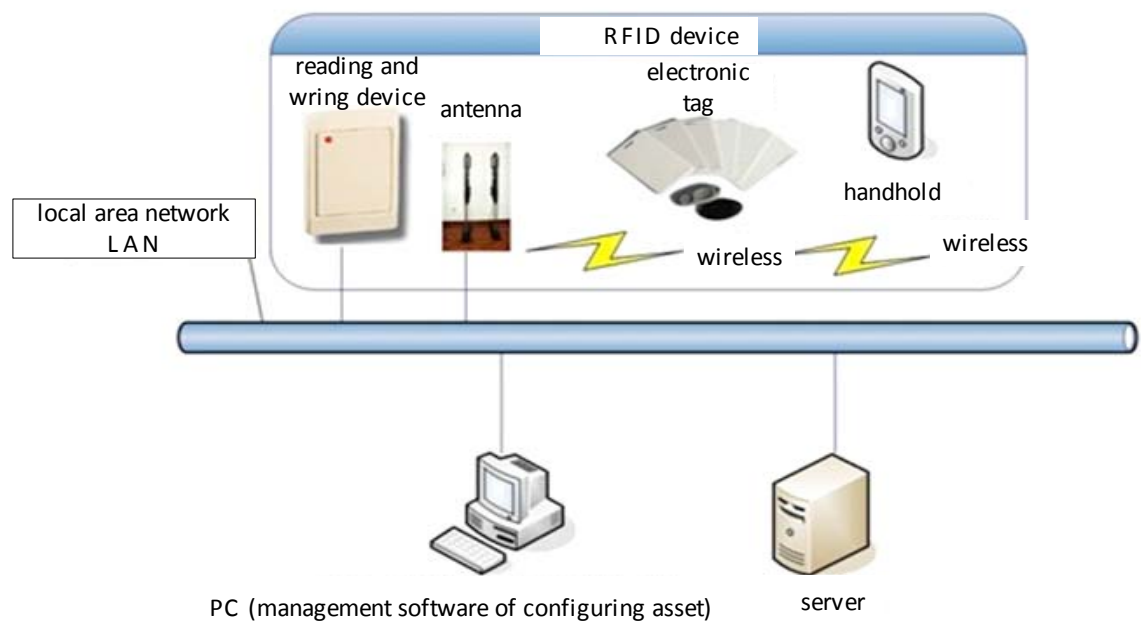

Fig. (4). The structure of the information management of RFID laboratory equipments.

ment and operations. Furthermore, it can effectively help managers to make accurate statistics of the number of laboratory equipments as well as related information, improving the efficiency of laboratory equipments and teaching quality.

\section{CONFLICT OF INTEREST}

The author confirms that this article content has no conflict of interest.

\section{REFERENCES}

[1] Shanghai Yingxin Information Technology Company, "Management Solutions for RFID Logistics and Supply Chain", Cards World, vol. 3, pp. 35-39, 2014.

[2] X. J. Hu, "RFID: the New Favorite of the era", China printing, vol. 4, pp. 49-51, 2006.
[3] X. F. Yu, "The Research and Implementation of Logistics Management System Based on the RFID technology", Harbin Institute of Technology, 2007.

[4] N. Xiao, W. L. Zheng, and W. L. Ma, "Design of Logistics Management System Based on RFID", Computer Technology and Development, vol. 18, no. 7, pp. 237-239, 2008.

[5] F. Q. Bai, "The Application of RFID Technology in Modern Logistics Management", Network Security Technology \& Application, vol. 4, pp. 36-38, 2014.

[6] Y. Chen, X. Zhang, and X. Hu, "Application of Long Distance RFID Technology in the Management of University Laboratory Equipment", Science \& Technology Information, vol. 32, pp. 3333, 2011.

[7] X. B. Mao, "The RFID Technical Application in College Laboratory Equipment asset Informative Management System", China Modern Educational Equipment, vol. 11, pp. 69-70, 2006.

[8] H. Qi, "Application of the RFID Technology in the Laboratory Equipment Automation Management System", Experimental Technology and Management, vol. 23, no. 3, pp. 179-181, 2009.

(C) Zhang and Reha; Licensee Bentham Open.

This is an open access article licensed under the terms of the Creative Commons Attribution Non-Commercial License (http://creativecommons.org/licenses/by-nc/3.0/) which permits unrestricted, non-commercial use, distribution and reproduction in any medium, provided the work is properly cited. 